\title{
Glandular amputation by strangulating tied suture: a case report of late-onset complication in the Plastibell circumcision technique
}

\author{
Jalil Hosseini ${ }^{1}$, Saeid Haghdani ${ }^{2}$ and Nima Narimani ${ }^{2 *}$ (D)
}

\begin{abstract}
Background: Circumcision is considered to be a procedure with minimal morbidity but may be associated with catastrophic complications in inexpert hands.

Case presentation: We presented a 9-year-old boy with a past medical history of circumcision at the age of one year with Plastibell clamp who was referred with severe chronic penile injury due to neglected plastibell string. After string removal under a loupe magnification (4X), we saw a deep circular injury at distal penile shaft which led to painless glandular autoamputation 45 days later. The patient was managed conservatively with daily urethral selfdilation until future reconstructive surgery.

Conclusion: This complication emphasized the importance of the follow-up visit by a physician for any probable string remnant.
\end{abstract}

Keywords: Circumcision, Plastibell, Complication

\section{Background}

Circumcision is the most common pediatric surgery worldwide, and performed due to cultural, religious and medical reasons [1]. It may be beneficial in reducing urinary tract infection, phimosis, balanitis, sexually transmitted infection and genital cancer [2]. Circumcision in newborn and in infancy has fewer complications due to their impressive healing capability and simpler techniques [3]. Complications of circumcision are usually minor and benign in most of the cases. However, there are reports about rare major complications with considerable morbidity, in which the treatment is challenging. In this case report, we present a 9-year-old boy with chronic penile injury due to a missed Plastibell string that finally lead to glandular autoamputation within one month after string removal.

\footnotetext{
* Correspondence: Nima_dr2001@yahoo.com; narimani.n@iums.ac.ir ${ }^{2}$ Department of Urology, Hasheminejad Kidney Center (HKC), Iran University of Medical Sciences (IUMS), Tehran, Iran
}

Full list of author information is available at the end of the article

\section{Case presentation}

A 9-year-old boy was brought to the urology clinic due to severe decreased urinary force and caliber since one month earlier. He has mentioned dysuria without other irritative lower urinary tract symptoms, intermittent hematuria, or downward urination. In past medical history, he was circumcised at the age of one year. In the physical examination, the glans, meatus and penile shaft seemed to be normal initially. Nevertheless, with precise inspection, a deep circular sharp cut in peno-glanular junction, was detected (Fig. 1). In the operating room, under local anesthesia and loupe magnification(X4), we detected a neglected Plastibell remnant string, which was removed with an eye scissor, and a 6 French Foley catheter was inserted in the urethra for two weeks. The patient was referred to a tertiary urethral and penile reconstructive center. Unfortunately, the penile glans auto amputation spontaneously occured after 45 days during the daily activity with minimal bleeding (Fig. 2). Foley catheter was again inserted for 2 weeks and a watch-full waiting approach for three months was recommended.

(c) The Author(s). 2019 Open Access This article is distributed under the terms of the Creative Commons Attribution 4.0 International License (http://creativecommons.org/licenses/by/4.0/), which permits unrestricted use, distribution, and reproduction in any medium, provided you give appropriate credit to the original author(s) and the source, provide a link to the Creative Commons license, and indicate if changes were made. The Creative Commons Public Domain Dedication waiver (http://creativecommons.org/publicdomain/zero/1.0/) applies to the data made available in this article, unless otherwise stated. 


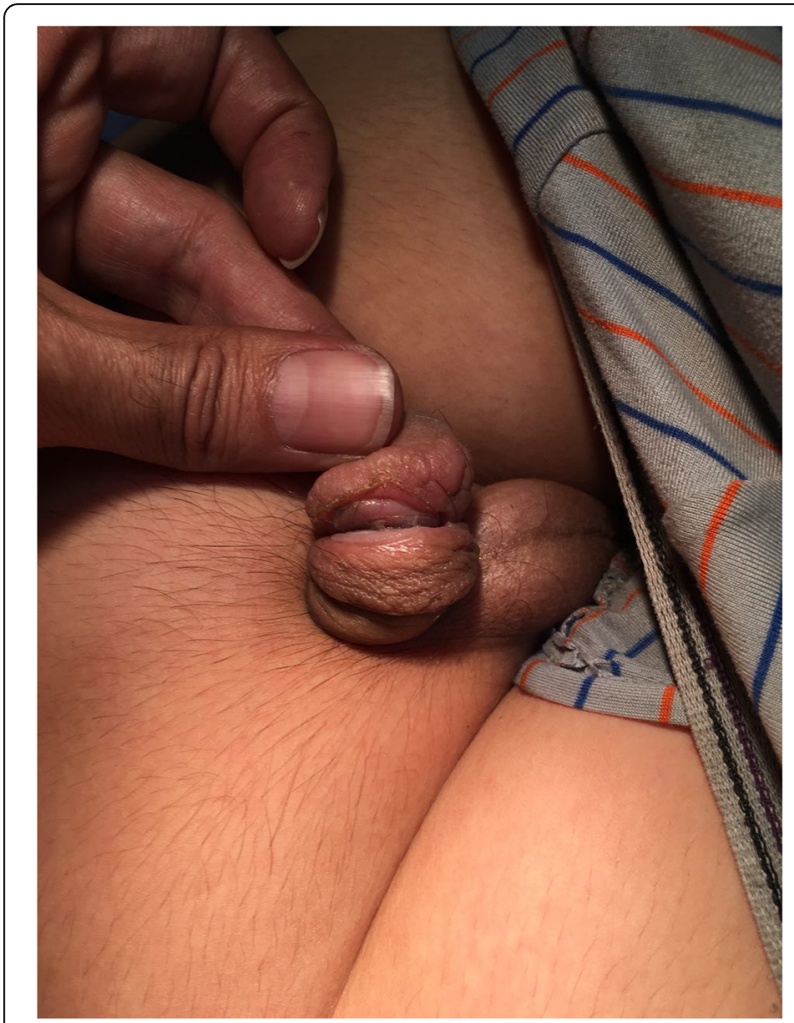

Fig. 1 A circular sharp cutting in the distal penile shaft, where the tied string usually is placed in plastibell circumcision

$\mathrm{He}$ is now managed conservatively with daily urethral self-dilation and is candidate for future reconstructive surgery.

\section{Discussion and conclusions}

Male circumcision is one of the most common surgical procedures worldwide, and is commonly performed in newborn and during infancy. The clamp-based techniques such as Gomco, Plastibell and Mogen clamp are the most popular circumcision methods in newborns [4]. The Plastibell technique was introduced in the 1950s and is the most common method for circumcision in our country [5]. The Plastibell consists of a plastic ring which is placed between the foreskin and the glans (to protect the glans from iatrogenic injury) and a string is used to clamp the foreskin into the groove in the ring. While this method is recommended for children under one year, open technique is used in a wide age range. However there are some reports about safety and feasibility of plastibell in older children [6]. The complication rate for circumcision varies widely from 0 to $16 \%$ [7]. They are categorized as early and late complications. While early complications mainly consist of bleeding, infection and unsatisfactory cosmetic results, the late ones are classified into the minor and major forms. Minor complications like meatal stenosis and penile adhesion can be managed easily, whereas the

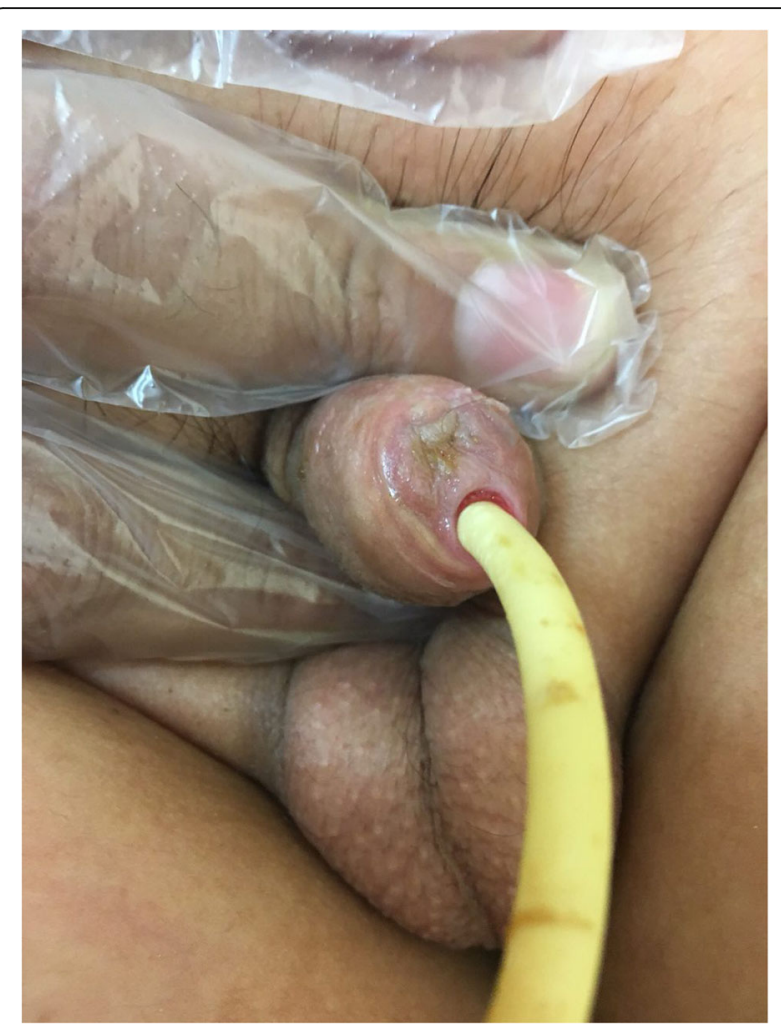

Fig. 2 The penis appearance after auto-amputated glans removal

treatment of major complications like extensive penile skin lost, urethrocutaneous fistula and penile amputation is quite challenging [8].

Glandular necrosis and amputation were previously reported as one of the most severe complications and were mostly due to use of electrocautery, sharp iatrogenic injury $[9,10]$ or the proximal migration of plastibell instrument [10]. To the best of our knowledge, this is the first case of complete glans autoamputation due to neglected remained plastibell hemostatic string, which occurred several years after circumcision. Although the parents are usually fully informed to bring back the child in the case of delayed plastibell falling off [11], a routine follow up visit (by an expert) in regards to string remnant has not been emphasized till now. We suggest that this exam should be performed (by the physician and not the parents) soon after the ring fell off, to prevent such catastrophic consequences.

\section{Acknowledgements}

Not applicable.

\section{Ethics approval and consent to participate}

A written informed consent was obtained from patient's parent.

\section{Authors' contributions}

$\mathrm{JH}$ in management decision of patient and revising of final manuscript, NN in in follow up the patient and drafting of manuscript and supervision of group, $\mathrm{SH}$ in data gathering and drafting of manuscript. All authors have read and approved this case report. 


\section{Funding}

No funding source.

\section{Availability of data and materials}

The datasets used during the current study are available from the corresponding author. The data are only images which are collected by corresponding author and permission for sharing is obtained from patient's parent.

\section{Consent for publication}

A written informed consent to publish was obtained from patient's parent.

\section{Competing interests}

The authors declare that they have no competing interests.

\section{Author details}

'Men's health and reproductive health research center, Shahid Beheshti University of Medical Sciences, Tehran, Iran. ${ }^{2}$ Department of Urology, Hasheminejad Kidney Center (HKC), Iran University of Medical Sciences (IUMS), Tehran, Iran.

Received: 8 April 2018 Accepted: 22 May 2019

Published online: 01 June 2019

\section{References}

1. Freeman JJ, Spencer AU, Drongowski RA, Vandeven CJ, Apgar B, Teitelbaum DH. Newborn circumcision outcomes: are parents satisfied with the results? Pediatr Surg Int. 2014;30(3):333-8.

2. Morris BJ, Kennedy SE, Wodak AD, Mindel A, Golovsky D, Schrieber L, Lumbers ER, Handelsman DJ, Ziegler JB. Early infant male circumcision: systematic review, risk-benefit analysis, and progress in policy. World J Clin Pediatr. 2017:6(1):89-102.

3. Weiss HA, Larke N, Halperin D, Schenker I. Complications of circumcision in male neonates, infants and children: a systematic review. BMC Urol. 2010;10:2

4. American Academy of Pediatrics Task Force on C. Male circumcision. Pediatrics. 2012;130(3):e756-85.

5. Wright JE. Non-therapeutic circumcision. Med J Aust. 1967;1(21):1083-6.

6. Bastos Netto JM, Goncalves de Araujo J Jr, Noronha MF, Passos BR, Lopes $\mathrm{HE}$, Bessa J Jr, Figueiredo AA. A prospective evaluation of plastibell(R) circumcision in older children. Int Braz J Urol. 2013;39(4):558-64.

7. Dave S, Afshar K, Braga LH, Anderson P. Canadian Urological Association guideline on the care of the normal foreskin and neonatal circumcision in Canadian infants (full version). Can Urol Assoc J. 2018:12(2):E76-99.

8. Pieretti RV, Goldstein AM, Pieretti-Vanmarcke R. Late complications of newborn circumcision: a common and avoidable problem. Pediatr Surg Int. 2010;26(5):515-8.

9. Krill AJ, Palmer LS, Palmer JS. Complications of circumcision. Sci World J. 2011;11:11.

10. Seleim HM, Elbarbary MM. Major penile injuries as a result of cautery during newborn circumcision. J Pediatr Surg. 2016;51(9):1532-7.

11. Bode $\mathrm{CO}$, Ikhisemojie $\mathrm{S}$, Ademuyiwa $\mathrm{AO}$. Penile injuries from proximal migration of the Plastibell circumcision ring. J Pediatr Urol. 2010;6(1):23-7.

\section{Publisher's Note}

Springer Nature remains neutral with regard to jurisdictional claims in published maps and institutional affiliations. 